\title{
Article
}

\section{Terahertz Rotational Spectroscopy of Greenhouse Gases Using Long Interaction Path-Lengths}

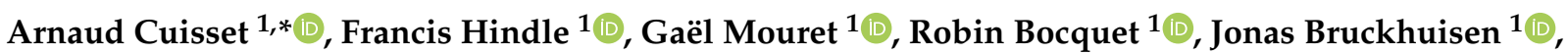

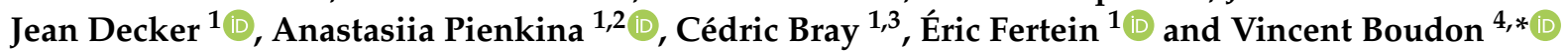

1 Laboratoire de Physico-Chimie de l'Atmosphère, UR 4493, LPCA, Université du Littoral Côte d'Opale, F-59140 Dunkerque, France; hindle@univ-littoral.fr (F.H.); mouret@univ-littoral.fr (G.M.); bocquet@univ-littoral.fr (R.B.); jonas.bruckhuisen@univ-littoral.fr (J.B.); jean.decker@univ-littoral.fr (J.D.); anastasiia.pienkina@univ-littoral.fr (A.P.); cedric.bray@umontpellier.fr (C.B.); fertein@univ-littoral.fr (É.F.); 2 SATT-Nord, 25, Avenue Charles Saint-Venant, F-59800 Lille, France

3 Laboratoire Charles Coulomb, UMR 5221 CNRS, Université de Montpellier, Campus Triolet, Place Eugène Bataillon, CEDEX 5, F-34095 Montpellier, France

4 Laboratoire Interdisciplinaire Carnot de Bourgogne, UM 6303 CNRS, Université de Bourgogne Franche-Comté, 9 Av. A. Savary BP47870, CEDEX, F-21078 Dijon, France

* Correspondence: arnaud.cuisset@univ-littoral.fr (A.C.); vincent.boudon@u-bourgogne.fr (V.B.)

Citation: Cuisset, A.; Hindle, F.; Mouret, G.; Bocquet, R.; Bruckhuisen, J.; Decker, J.; Pienkina, A.; Bray, C.; Fertein, É.; Boudon, V. Terahertz Rotational Spectroscopy of Greenhouse Gases Using Long Interaction Path-Lengths. Appl. Sci. 2021, 11, 1229. https:// doi.org/10.3390/app11031229

Academic Editor: Giulio Cerullo Received: 18 December 2020 Accepted: 26 January 2021 Published: 29 January 2021

Publisher's Note: MDPI stays neutral with regard to jurisdictional clai$\mathrm{ms}$ in published maps and institutional affiliations.

Copyright: (C) 2021 by the authors. Licensee MDPI, Basel, Switzerland. This article is an open access article distributed under the terms and conditions of the Creative Commons Attribution (CC BY) license (https:// creativecommons.org/licenses/by/ $4.0 /)$.

\begin{abstract}
Even if on-board mm-wave/THz heterodyne receivers have been developed to measure greenhouse gases (GHGs) atmospheric profiles, rotational spectroscopy rests under-exploited for their monitoring unlike IR rovibrational spectroscopy. The present study deals with the ability of $\mathrm{THz}$ spectroscopy using long interaction path-lengths for GHG laboratory investigations. Highresolution $\mathrm{THz}$ signatures of non-polar greenhouse molecules may be observed by probing very weak centrifugal distortion induced rotational transitions. To illustrate, new measurements on $\mathrm{CH}_{4}$ and $\mathrm{CF}_{4}$ have been carried out. For $\mathrm{CH}_{4}$, pure rotational transitions, recorded by $\mathrm{cw}-\mathrm{THz}$ photomixing up to $2.6 \mathrm{THz}$ in a White type cell adjusted to $20 \mathrm{~m}$, have allowed to update the methane line list of atmospheric databases. Concerning $\mathrm{CF}_{4}$, Fabry-Perot $\mathrm{THz}$ absorption spectroscopy with a $\mathrm{km}$ effective pathlength was required to detect line intensities lower than $10^{-27} \mathrm{~cm}^{-1} /\left(\right.$ molec cm $\left.{ }^{-2}\right)$. Contrary to previous synchrotron-based FT-FIR measurements, the tetrahedral splitting of $\mathrm{CF}_{4} \mathrm{THz}$ lines is fully resolved. Finally, quantitative measurements of $\mathrm{N}_{2} \mathrm{O}$ and $\mathrm{O}_{3}$ gas traces have been performed in an atmospheric simulation chamber using a submm-wave amplified multiplier chain coupled to a Chernin type multi-pass cell on a $200 \mathrm{~m}$ path-length. The $\mathrm{THz}$ monitoring of these two polar GHGs at tropospheric and stratospheric concentrations may be now considered.
\end{abstract}

Keywords: greenhouse gases; terahertz; long interaction path-lengths; rotational spectroscopy; trace gas monitoring

\section{Introduction}

The main discussion on climate change tends to focus on carbon dioxide $\left(\mathrm{CO}_{2}\right)$, the most dominant Greenhouse Gas (GHG) (65\% of the global emission) produced by the burning of fossil fuels, industrial processes and changes in land use (deforestation, intensification of agriculture, flooding, etc.) [1]. However, $\mathrm{CO}_{2}$ is not the only GHG driving the global climate change: methane $\left(\mathrm{CH}_{4}\right)$, nitrous oxide $\left(\mathrm{N}_{2} \mathrm{O}\right)$, tropospheric ozone $\left(\mathrm{O}_{3}\right)$ and fluorinated gases have a direct contribution to the greenhouse effect. In particular, the radiative forcing (warming influence) of long-lived GHGs such as tetrafluoromethane $\left(\mathrm{CF}_{4}\right)$ with a 50,000 years lifetime in earth's atmosphere [2], is undergoing accelerating growth (almost a third of the increase attributed to the industrial age has been over the past 30 years) $[3,4]$. Several currently operating satellite and air-borne missions aim to estimate emissions and absorptions of the main GHGs. By monitoring the column densities in our atmosphere, they accumulate new knowledge of their global distribution 
and temporal variation. Fourier Transform Spectrometers (FTS) are the most popular instruments used in these missions analysing the IR radiations reflected from the Earth's surface and emitted from the atmosphere and the surface. We can mention: (i) the IASI interferometer in the European MetOp satellite which monitors $\mathrm{CO}_{2}, \mathrm{O}_{3}, \mathrm{CH}_{4}, \mathrm{~N}_{2} \mathrm{O}$ GHG column amounts in several IR channels of detection [5]; (ii) ACE on board the Canadian Satellite SCISAT where $\mathrm{CF}_{4}$ and others CFCs/HCFCs are retrieved routinely in addition to the most abundant GHGs [6]; (iii) TES on board the Aura spacecraft which retrieves the $\mathrm{O}_{3}$ and $\mathrm{CH}_{4}$ profiles in the lower atmosphere from their rovibrational signatures [7]. Among the Aura's instruments, there is also a passive microwave limb-sounding (MLS) radiometer/spectrometer used to measure the pollution in the upper troposphere in the presence of ice clouds and volcanic aerosols, which prevent measurements by IR/UV techniques. The MLS instrument monitors $\mathrm{O}_{3}$ and $\mathrm{N}_{2} \mathrm{O}$ by measuring pure rotational lines in the $\mathrm{mm}$-wave $(240 \mathrm{GHz})$ and in the submm-wave $(640 \mathrm{GHz})$ domains, respectively [8]. More recently, the National Space Science Center of the Chinese Academy of Sciences has developed a THz Atmospheric Limb Sounder (TALIS) for atmospheric vertical resolved profile observations: as for MLS/Aura, $\mathrm{O}_{3}$ and $\mathrm{N}_{2} \mathrm{O}$ are the targeted GHGs and their rotational transitions are probed with four heterodyne radiometers ( $\mathrm{LO}$ frequencies: $118 \mathrm{GHz}$, $190 \mathrm{GHz}, 240 \mathrm{GHz}$ and $643 \mathrm{GHz}$ ) and several FFT spectrometers of $2 \mathrm{GHz}$ bandwidth with $2 \mathrm{MHz}$ resolution [9]. With this instrument, they are able to retrieve the $\mathrm{N}_{2} \mathrm{O}$ and $\mathrm{O}_{3}$ profiles with average precisions lower than $10 \%$ and $5 \%$ from 10 to $42 \mathrm{~km}$ and from 10 to $70 \mathrm{~km}$ altitude, respectively.

Accurate $\mathrm{THz}$ laboratory measurements are required in order to provide the best set of GHGs rotational line parameters (frequencies, widths, intensities...) and to optimize the inversion processes in GHGs atmospheric concentrations retrieval. The quality of the fits depends directly on the SNR of high resolution $\mathrm{THz}$ spectra and consequently on the sensitivity of the spectrometers [10]. According to the Beer-Lambert law, longer interaction $\mathrm{THz}$ path-lengths are required in the situation of a weak absorption. With longer wavelengths and larger beamsizes, the control of the propagation of $\mathrm{THz}$ radiations on long-range beam paths is challenging compared to that carried out in the IR/UV regions. Nevertheless, recent progress has allowed gas phase $\mathrm{THz}$ spectroscopy experiments with molecules/beam interaction distances from several tens to several hundreds of meters [11] to be performed. This article highlights recent advances of $\mathrm{THz}$ spectroscopy performed by our group, using long-interaction path-lengths for the measurement of weak GHG rotational absorptions. The ability to measure fully resolved centrifugally induced rotational transitions of non polar GHGs such as $\mathrm{CH}_{4}$ and $\mathrm{CF}_{4}$ will be demonstrated and the first $\mathrm{THz}$ measurements in an atmospheric simulation chamber will be presented towards the detection of polar stable $\mathrm{N}_{2} \mathrm{O}$ and unstable $\mathrm{O}_{3}$ GHGs at trace levels.

\section{Materials and Methods}

With the exception for the production of ozone, commercially available high purity $\mathrm{CH}_{4}, \mathrm{~N}_{2} \mathrm{O}$, and $\mathrm{CF}_{4} \mathrm{GHGs}$ with natural isotopic abundances were used throughout. The ozone was produced by corona discharge generation with pure oxygen (Air Tree Ozone Technology, C-Lasky C-L010-DTI). Various THz sources and detectors have been used in the studies presented here. In particular, three commonly used approaches, optical, optoelectronic and electronic, have been employed for the generation of the $\mathrm{THz}$ radiation.

\subsection{Synchrotron Based FT THz Spectroscopy}

The AILES beamline of the SOLEIL synchrotron was used for high-resolution broadband FT measurements in the 0.6 to $19.5 \mathrm{THz},\left(20-650 \mathrm{~cm}^{-1}\right)$ spectral range on $\mathrm{CH}_{4}$ and $\mathrm{CF}_{4}$. The very bright light extracted from the synchrotron bending magnet has the advantage of displaying a lower divergence compared with other sources aiding its use with long path interaction White type cells. The FT IFS125 spectrometer, used in this case, has a $5 \mathrm{~m}$ delay stage allowing a resolution of $30 \mathrm{MHz}$ to be achieved [12]. 


\subsection{Cw-THz Spectroscopy by Photomixing}

Alternatively, higher resolution measurements can be made using monochromatic $\mathrm{THz}$ sources. The generation of $\mathrm{THz}$ radiation by photomixing is a frequency downconversion technique which was used for the measurements of individual rotational lines of $\mathrm{CH}_{4}$ up to $2.6 \mathrm{THz}$ [13]. Two extended cavity laser diodes operating around $780 \mathrm{~nm}$ are mixed together in a LTG-GaAs device. The lasers are detuned to the desired $\mathrm{THz}$ frequency inducing a corresponding current in the photomixer device which is coupled to an integrated log spiral antenna [14]. The radiation is pre-colimated by a silicon hyperhemispherical lens and propagated in free space. This type of source is monochromatic with excellent spectral purity and can be used in the range of $100 \mathrm{GHz}$ to $3.3 \mathrm{THz}$. The available power is limited to $0.1 \mathrm{nW}$ from $2.5 \mathrm{THz}$. By locking onto a frequency comb, the generated $\mathrm{THz}$ frequency is determined with a $\mathrm{kHz}$ accuracy [15]. Both amplitude and frequency modulation schemes can be easily implemented with this source, it does however suffer from available low power levels at the highest frequencies.

\subsection{Submm-Wave Spectroscopy with Amplified Multiplier Chains}

We used two AMC from the Virginia Diodes Inc. as electronic sources for the submmwave measurements coupled to CHARME (see Section 3.2) and to the THz FP cavity (see Section 3.3). They are based on the up-conversion of a synthesized microwave frequency using a cascade of Schottky diode frequency multipliers mounted in rectangular waveguide blocks. The guided radiation is launched into free space using a horn antenna and propagated through the interaction cell. Frequencies from $100 \mathrm{GHz}$ to $1 \mathrm{THz}$ can be conveniently produced and easily modulated in either amplitude or frequency as desired [16]. A typical power of $50 \mu \mathrm{W}$ is available at $600 \mathrm{GHz}$.

\subsection{Detection Schemes}

For all experiments, two types of detector were employed. The Zero Biased Detector (ZBD) is an unbiased Schottky diode mounted in a wave-guide operating in detection mode. This type of detector is uncooled and can provide a typical NEP of $10 \mathrm{pW} / \sqrt{\mathrm{Hz}}$. When greater sensitivity was required a Helium cooled bolometer was used with a NEP of $1 \mathrm{pW} / \sqrt{\mathrm{Hz}}$. For the measurements of very weakly intense $\mathrm{CF}_{4}$ lines, we coupled a very high finesse FP cavity with an AMC in order to reach very long equivalent interaction paths (see Section 3.3). A control loop is used to lock the cavity to the frequency of the AMC with a frequency modulation providing an error signal. The second harmonic of the frequency modulation is simultaneously exploited to detect the presence of molecular absorption present in the cavity. The AMC frequency and cavity are thus swept together allowing sensitive absorption measurements to be made [17].

\section{Results and Discussion}

\section{1. $\mathrm{THz}$ Measurements of $\mathrm{CH}_{4}$ in a White Type Multi-Pass Cell}

THz long-path spectroscopic experiments were initially conducted in the 2000's using home-made or commercial White type gas cells. The White cell was first described in 1942 by John U. White [18] and was a significant improvement over previous long path measurement techniques used in optical spectroscopy. A White cell is constructed using three spherical, concave mirrors with the same radius of curvature. The mirrors are separated by a distance equal to their radii of curvature. FT Michelson-based interferometers have been connected by different groups to White type gas cells allowing improving the detection sensitivity in the Far-IR domain. The THz pathlengths reached vary from several tens of meters with classical sources such as Hg lamps [19,20] up to $180 \mathrm{~m}$ with weakly divergent and high brigthness Far-IR synchrotron radiations [12,21]. As example, the White type cell connected to the Bruker IFS125 high-resolution interferometer coupled to the AILES Far-IR/THz beamline of the SOLEIL synchrotron is shown in Figure 1 (right part). Optoelectronic $\mathrm{THz}$ sources have been also coupled to White type cells to attempt $\mathrm{THz}$ rotational transitions measurements with long pathlengths (see Figure 1, left part). 
Ppm and subppm LOD of strongly polar compounds were reached in pulsed THz-TDS

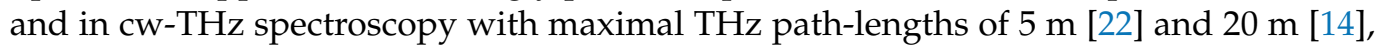
respectively.

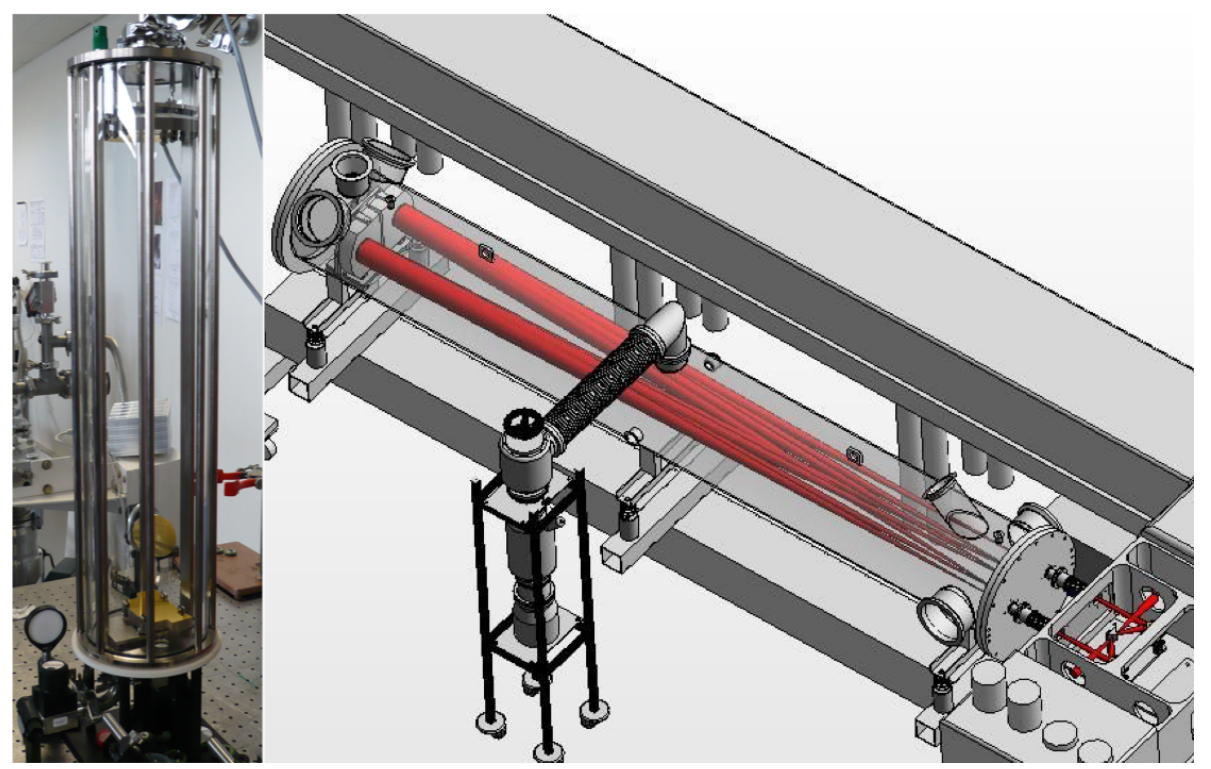

Figure 1. Picture/Scheme of the two White-type gas cells used for the $\mathrm{CH}_{4}$ rotational spectra measurements. Left: standard White-type cell (Infrared Analysis, 35-V) used in the cw-THz photomixing measurement [14]. Right: White-type cell located in the AILES beamline of the SOLEIL synchrotron [12].

To date, the spectroscopic investigation of pure rotational $\mathrm{THz}$ transitions of $\mathrm{CH}_{4}$ provides probably the best results in terms of sensitivity obtained by coupling $\mathrm{cw}-\mathrm{THz}$ sources with White-type cells. Even if $\mathrm{CH}_{4}$ is not polar, centrifugal distortion and vibrational effects induce a weak dipole $(\simeq 1 \mu \mathrm{D})$ which allows transitions between rotational energy levels. So very weak rotational absorptions in the $\mathrm{THz}$ domain may be measured with an optimized level of sensitivity. Using the HITRAN database and its graphical tool "HITRAN on the web" $[23,24]$, the rotational absorbance of pure methane has been modelled in Figure 2 (main panel) in the $2.0-2.7 \mathrm{THz}$ frequency range for a $\mathrm{THz}$ path length of $20 \mathrm{~m}$ and a pressure of $10 \mathrm{mbar}$. The $\mathrm{THz}$ spectroscopy of $\mathrm{CH}_{4}$ requires the measurements of very weak rotational absorptions lower than $2 \times 10^{-5} \mathrm{~cm}^{-1}$ in a THz frequency region difficult to access. FT-Far-IR synchrotron-based spectroscopy $[21,25]$ and $\mathrm{cw}-\mathrm{THz}$ by photomixing [13] succeeded to measure these weak rotational lines (see insets Figure 2) with $150 \mathrm{~m}$ and $20 \mathrm{~m}$ pathlengths, respectively. The White type multi-pass gas cells shown in Figure 1 were used to reach these long interaction distances and to increase the $\mathrm{THz}$ absorbances. While the FT-Far-IR rotational lines are limited by the maximal resolution of the high-resolution interferometer (around $30 \mathrm{MHz}$ ), the $\mathrm{THz} \mathrm{CH}_{4}$ lines measured by $\mathrm{cw}-\mathrm{THz}$ spectroscopy are fully resolved and Doppler limited. These $\mathrm{THz}$ frequencies resulting from the gaussian fit of the low-pressure line profile have improved the accuracies of the ground state and the $v_{4} \leftarrow v_{4}$ hot band molecular parameters allowing a better global modelling of the $\mathrm{CH}_{4}$ emission and absorption used to determine the molecular abundance of this major GHG in Earth's atmosphere and also in various (exo)planetary upper atmospheres [21,26]. 

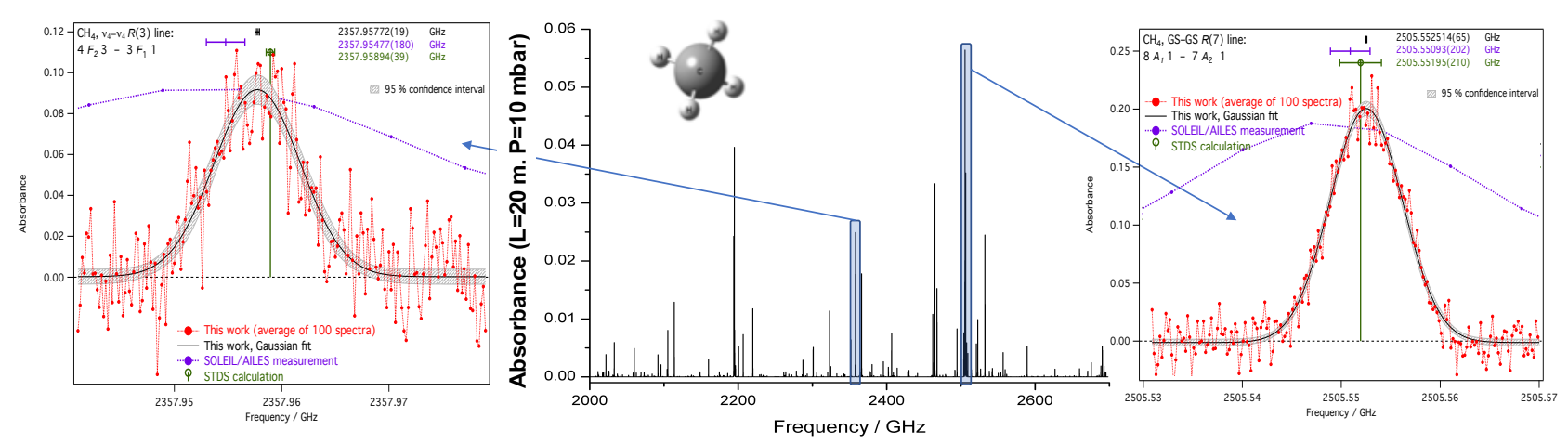

Figure 2. Central part: Absorption of ground state rotational $\mathrm{THz}$ lines of $\mathrm{CH}_{4}$ induced by centrifugal distortion simulated for a pathlength of $20 \mathrm{~m}$. and a pressure of $10 \mathrm{mbar}$. Left and right parts: two examples of experimental lines measured at $30 \mathrm{MHz}$ resolution, $P=10 \mathrm{mbar}$ and $L=150 \mathrm{~m}$ by FT-FIR spectroscopy using the AILES beamline of the SOLEIL synchrotron (blue solid line) and at $30 \mathrm{kHz}$ resolution, $P=1.5 \mathrm{mbar}$ and $L=20 \mathrm{~m}$ with the cw-THz photomixing spectrometer [13]. Calculations were performed using the STDS software [27], which is part of the XTDS [28] package that implements the tensorial formalism developed for spherical-top molecules in the Dijon group.

\subsection{Trace Gases THz Measurements of $\mathrm{N}_{2} \mathrm{O}$ and $\mathrm{O}_{3}$ in an Atmospheric Simulation Chamber Equipped with a Chernin Type Multi-Pass Cell}

A ppm LOD is required to monitor $\mathrm{CH}_{4}$ in our atmosphere. Due to the weak intensities of pure rotational lines, $\mathrm{THz}$ spectroscopic monitoring of methane at atmospheric concentrations would prove serious difficulties even after a strong improvement of the spectrometers sensitivity. On the contrary, the THz trace gas detection of polar GHGs already proved its capability by the monitoring of $\mathrm{N}_{2} \mathrm{O}$ and $\mathrm{O}_{3}$ in the stratosphere with the MLS and TALIS sounders $[8,9]$. These THz heterodyne receivers are able to determine atmospheric subppm concentration profiles in the submm- and in the mm-wave domains. A possibility to get close to the detection levels of $\mathrm{N}_{2} \mathrm{O}$ and $\mathrm{O}_{3}$ is demonstrated in this study by performing the first $\mathrm{THz}$ absorption measurements in an atmospheric simulation chamber.

Compared to $\mathrm{CH}_{4}$, rather strong rotational transitions of $\mathrm{N}_{2} \mathrm{O}$ and $\mathrm{O}_{3}$, with intensities around $10^{-22} \mathrm{~cm}^{-1} /\left(\right.$ molecule $\left.\mathrm{cm}^{-2}\right)$ [23] were probed in the submm-wave domain using versatile spectrometers based on AMC [16]. Nevertheless, with increasing wavelengths, the $\mathrm{THz}$ beam divergence rises and long path $\mathrm{THz}$ absorption experiments becomes challenging. Recently, promising results have been obtained with compact circular multi-pass cells able to refocus the beam at each internal reflection: (i) in Ref. [29], Rothbart et al., using a AMC, have measured traces of acetaldehyde in methanol down to $110 \mathrm{ppm}$ with an optical path of $1.9 \mathrm{~m}$ in the $250 \mathrm{GHz}$ region; (ii) in Ref. [11], Kim et al., using THz-TDS, have recorded the pure rotational spectrum of $\mathrm{N}_{2} \mathrm{O}$ at atmospheric pressure with a dilution of $1 \%$ by reaching a THz path of $18.61 \mathrm{~m}$. Even if the results of these studies are interesting since they were obtained without pre-concentration in a very compact and easily transportable gas cell, the LOD reached is clearly not sufficient for trace gas detection in the atmosphere. Yet it is possible to reach lower LOD with longer $\mathrm{THz}$ path-lenghts using a multi-pass cell based on the clever Chernin arrangement [30]. Compared to the White type arrangement discussed in the previous section, a Chernin multi-pass cell optimizes the recirculating of the beam over many focused lines on the field mirrors [31]. In particular longer wavelengths are very critical due to the overlapping between adjacent refocusing points within the cell what needs to be avoided or at least limited in order to prevent the presence of stationary waves yielding to baseline variations. Moreover the optical path-length in the Chernin arrangement is easy to adjust with a matrix distribution of the refocusing points and a variable number of rows and columns. As shown in Figure 3, we dimensioned a Chernin multi-pass cell in order to integrate it in CHARME (Chamber for the Atmospheric Reactivity and the Metrology of the Environment), a $9.2 \mathrm{~m}^{3}$, evacuable cylinder used to simulate the physical-chemistry of the atmosphere in a controlled environment [32]. 
The Chernin type optical setup called hereafter "MultiCHARME" is composed of 5 mirrors ( 2 rectangular field mirrors and 3 spherical objective mirrors) each with $5 \mathrm{~m}$ radius of curvature corresponding to the $5 \mathrm{~m}$ baselength of CHARME. All mirror holders are equipped with computer-controlled micrometric screws for optical adjustments and path length changes. MultiCHARME was designed to be coupled with different spectrometers covering a very large spectral range from visible to sub-mm wavelengths.

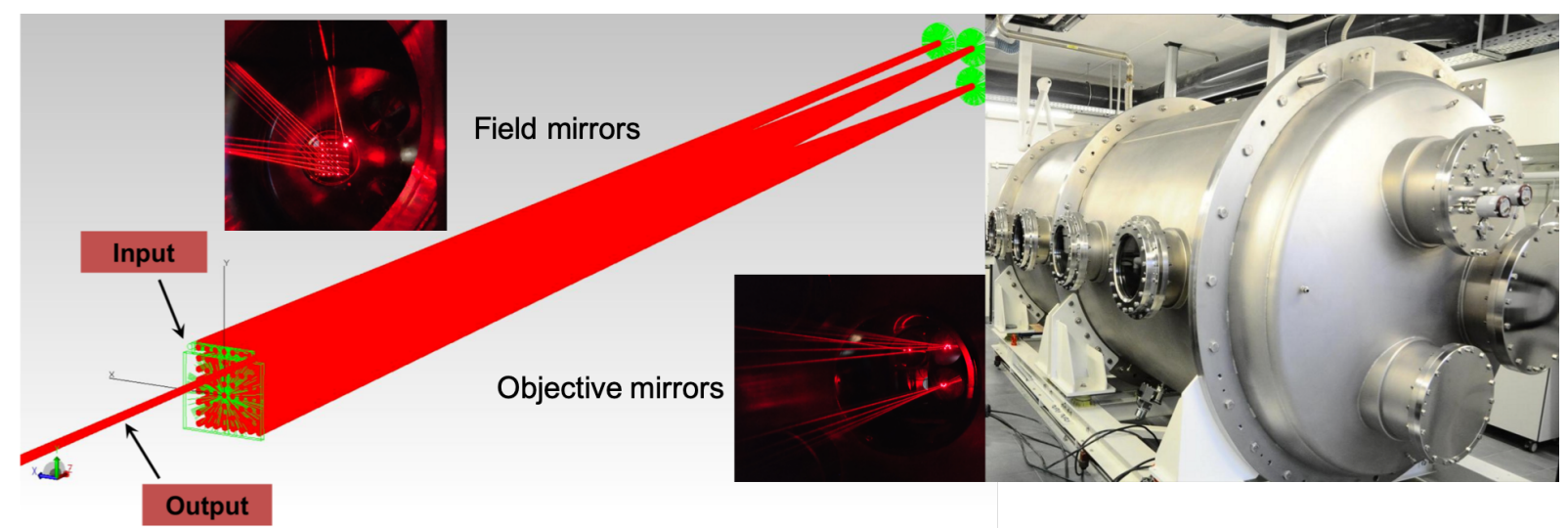

Figure 3. Left: Scheme of the MULTICHARME Chernin cell with pictures, inside CHARME, of the $6 \times 6$ arrangement highlighted with a He-Ne laser on the 2 fields and 3 objective mirrors. Right: external view of CHARME: CHamber for Atmospheric Reactivity and Metrology of the Environment located in the LPCA, Dunkirk, France.

$\mathrm{N}_{2} \mathrm{O}$ was chosen as a test molecule to characterize the performance of MultiCHARME on three frequency decades. In particular, the linearity of the absorption was checked with rovibrational measurements up to $480 \mathrm{~m}$ in the near-IR and with rotational measurements up to $240 \mathrm{~m}$ in the $\mathrm{THz}$ domain [33]. In Figure 4, a rotational absorbance of $32 \%$ at $577.58 \mathrm{GHz}$ ( $\mathrm{P}=0.7 \mathrm{mbar}$ ) is obtained by measuring in CHARME $400 \mathrm{ppm}$ of residual $\mathrm{N}_{2} \mathrm{O}$ traces with a $\mathrm{THz}$ path-length adjusted to $200 \mathrm{~m}$ (configuration $4 \times 5$ on the field mirror). Measurements of ozone at a trace level of $200 \mathrm{ppm}$ were also performed in the same configuration with an absorbance of $25 \%$ at $577.58 \mathrm{GHz}(\mathrm{P}=1 \mathrm{mbar})$. We benefited from the possibility to simultaneously modulate the amplitude and frequency of the AMC. It was of particular utility to minimise the effects of the standing waves disturbing the baseline spectra measured in MultiCHARME. A rapid frequency modulation was applied with a depth corresponding to the FSR of the interaction length. The absorption profiles of the targeted lines displayed a collisional broadening in excess of this FSR. The profiles were measured using a significantly slower amplitude modulation and a lock-in amplifier to extract the correct modulation frequency. In the right part of Figure 4, the absorbances of $\mathrm{N}_{2} \mathrm{O}$ and $\mathrm{O}_{3}$, respectively at typical tropospheric and stratospheric concentrations have been simulated with HITRAN on the web [24]. Absorption levels lower than $1.0 \times 10^{-8} \mathrm{~cm}^{-1}$ and $2.5 \times 10^{-7} \mathrm{~cm}^{-1}$ should be reached to measure, respectively, tropospheric $\mathrm{N}_{2} \mathrm{O}$ and stratospheric $\mathrm{O}_{3}$. With a $\mathrm{THz}$ path-length of $200 \mathrm{~m}$, the associated absorbances are respectively 2000 times and 50 times weaker that those measured with MultiCHARME. The capability to monitor $\mathrm{N}_{2} \mathrm{O}$ and $\mathrm{O}_{3}$ with typical atmospheric concentrations depend now on a correct modelisation of the subsisting baseline variations due to long path FP effects. By removing these baseline oscillations, we can reasonably hope to reach sufficient $\mathrm{SNR}$ to monitor $\mathrm{O}_{3}$ in CHARME at stratospheric concentration with the same setup. The measurement of tropospheric $\mathrm{N}_{2} \mathrm{O}$ requires to improve by at least two orders of magnitude the LOD. Finally, we can notice that the LOD actually reached using $\mathrm{THz}$ spectroscopy in MultiCHARME is already sufficient to monitor $\mathrm{N}_{2} \mathrm{O}$ collected in specific polluted atmosphere such as dental office where the waste anesthetic $\mathrm{N}_{2} \mathrm{O}$ exposure could reach several hundreds of ppm without adapted extractors [34]. 


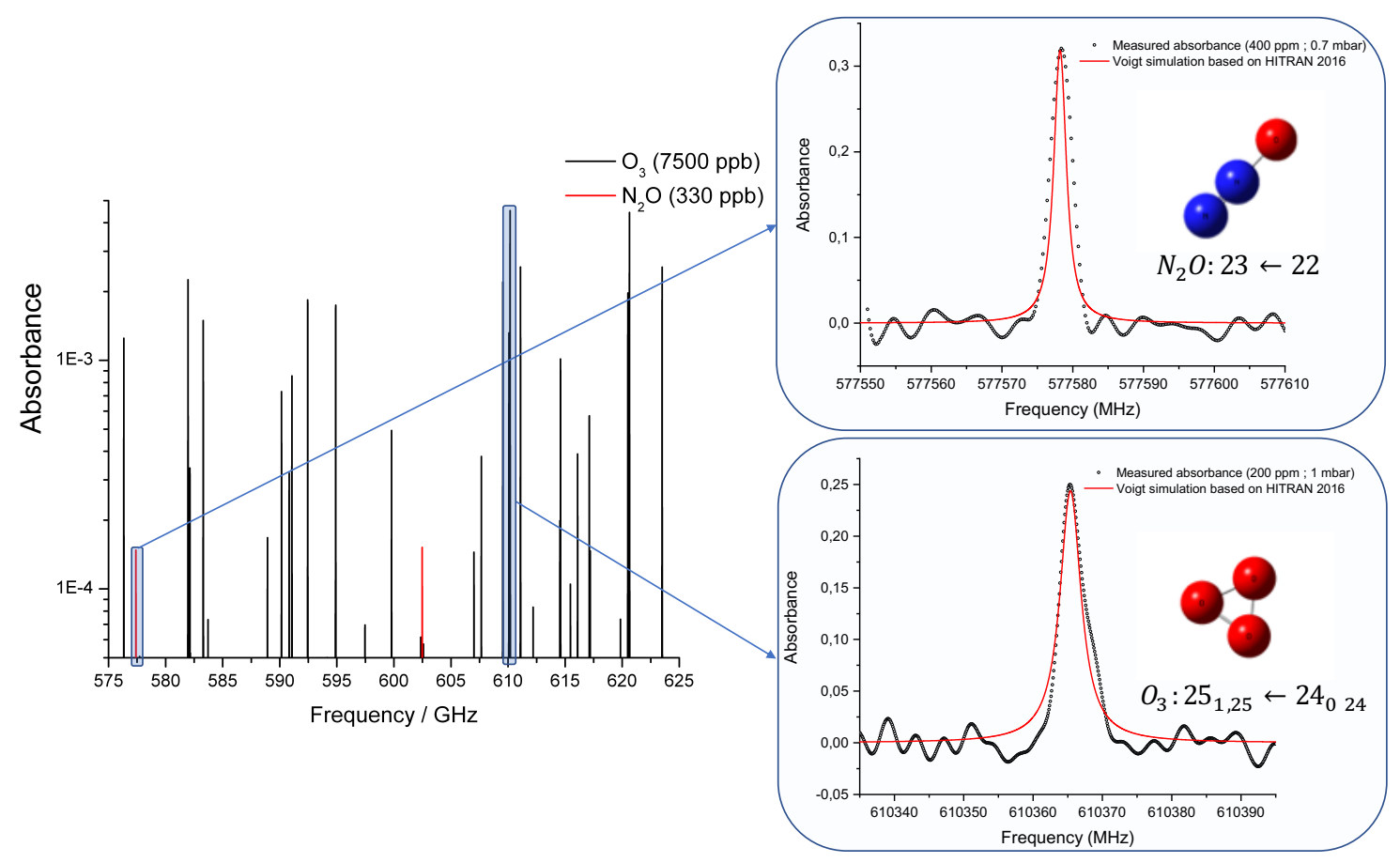

Figure 4. Left: Simulation of the rotational absorption in the 575-625 frequency region of $\mathrm{N}_{2} \mathrm{O}$ and $\mathrm{O}_{3}$ at tropospheric (330 ppb) and stratospheric (7.5 ppm) concentrations, respectively, for a THz pathlength of $200 \mathrm{~m}$. Right: $400 \mathrm{ppm}$ of $\mathrm{N}_{2} \mathrm{O}$ at $P=0.7$ mbar and $200 \mathrm{ppm}$ of $\mathrm{O}_{3}$ at $P=1.0$ mbar measured in CHARME with the MultiCHARME setup in a $4 \times 5$ Chernin configuration providing a THz pathlength of $200 \mathrm{~m}$ (black open circles). Both lines have been measured with an amplitude modulated at $4.5 \mathrm{kHz}$. An additional frequency modulation at $50 \mathrm{kHz}$ with a $1.1 \mathrm{MHz}$ depth was added to limit the baseline oscillations. The red solid lines correspond to Voigt profiles simulated with HITRAN2016 tabulated frequencies, linewidths and intensities.

\subsection{Intra-Cavity $\mathrm{THz}$ Measurements of $\mathrm{CF}_{4}$}

In the previous sections, we showed that multi-pass cells provide higher sensitivity for the measurements of weak rotational resonances or small number of absorbing molecules leading to $\mathrm{THz}$ line with low intensities. However, these cells are limited by a significant attenuation of the input $\mathrm{THz}$ power and generally require large volumes to reach distances exceeding $100 \mathrm{~m}$. An alternative approach is to adapt the intra-cavity techniques developed in the IR domain to the longer wavelengths of the THz/submm-wave spectral domains. In 2019, our group challenges this feat by developing a THz resonator based on a low-loss oversized corrugated waveguide closed with highly reflective photonic mirrors made from silicon discs [17]. The length of the cavity is finely adjusted using piezo-electric actuators to move the mirrors by up to $250 \mu \mathrm{m}$, a control loop locks the cavity length to the $\mathrm{THz}$ frequency. With Fabry-Perot THz absorption spectroscopy (FP-TAS), we were able to perform gas phase measurements with a finesse better than 3000 in the $620 \mathrm{GHz}$ frequency range. With such high-finesse, an equivalent interaction length of $1 \mathrm{~km}$ is estimated with a cavity of $48 \mathrm{~cm}$ long. It was demonstrated by measurements on a low abundant OCS isotopologue that FP-TAS is clearly able to measure transitions with intensities of about $10^{-27} \mathrm{~cm}^{-1} /\left(\right.$ molec $\left.\mathrm{cm}^{-2}\right)$. A scheme and a picture of the THz FP cavity is given in Figure 5. We can notice that the quality of the cavity should be optimised and must remain stable to perform quantification. The measured signal is not directly the molecular absorption it is the second harmonic of a frequency modulated THz. It indicates the strength and width of the cavity mode as it scans across the molecular line. The absorption by the molecule causes a reduction in the signal allowing the line centre to be reliably determined and quantification undertaken for a given cavity configuration. For all these reasons, a step of calibration is still required. 
Corrugated waveguide

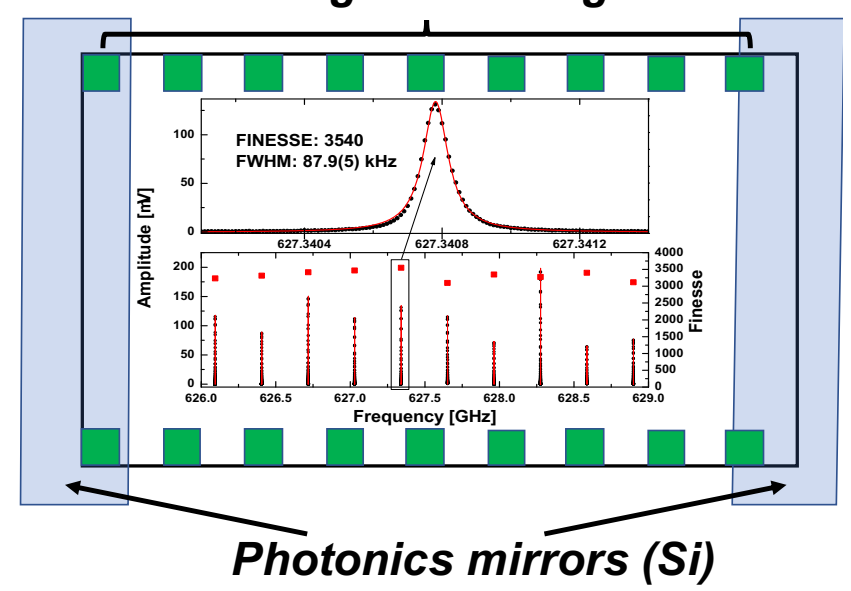

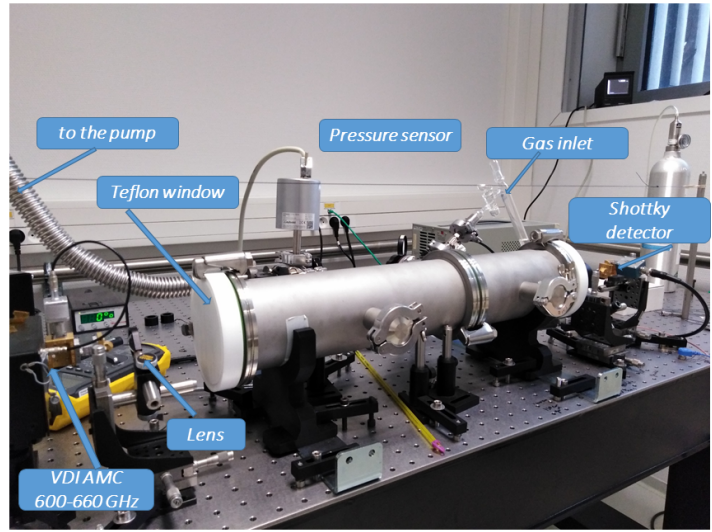

Figure 5. Left: Scheme of the Fabry-Perot THz cavity based on a low-loss oversized corrugated waveguide with highly reflective photonic mirrors. Successive cavity modes are shown inside the cavity scheme and an achieved finesse above 3500 in the $626-629 \mathrm{GHz}$ frequency range is highlighted $\left(L_{e f f} .>1.1 \mathrm{~km}\right)$. Right: Picture of the FP-THz absorption spectrometer with some legends.

In the present article, we present new measurements performed with this cavity on $\mathrm{CF}_{4}$ a very stable GHG, with a high greenhouse warming potential (>6500) [2]. As for $\mathrm{CH}_{4}, \mathrm{CF}_{4}$ is not polar and only rotational transitions induced by centrifugal distortion or vibrational anharmonicity may be observed. Compared to $\mathrm{CH}_{4}$, the heavier $\mathrm{CF}_{4}$ molecule exhibits ground state pure rotational transitions at lower frequencies with a maximum intensity around $650 \mathrm{GHz}$. According to ab initio parameters [35], the distortion-induced dipole is estimated to only $0.324 \mu \mathrm{D}$. Therefore, all the $\mathrm{THz}$ lines are very weak with intensities never exceeding $10^{-27} \mathrm{~cm}^{-1} /\left(\right.$ molec $\left.\mathrm{cm}^{-2}\right)$. At room temperature, rotational transitions belonging to the hot band $v_{3}=1$ are slightly more intense compared to the ground state transitions. Rotational clusters in the $R$ branch of this band were measured by FT-THz spectroscopy based on synchrotron source with a path-length of $150 \mathrm{~m}$ in the White-type cell shown in Figure 1 (right part) [36]. In this study, the observation of $\mathrm{CF}_{4}$ rotational clusters has required to co-add more than 5000 spectra measured at middle resolution $\left(0.01 \mathrm{~cm}^{-1}\right)$ and pressure-broadened at $\mathrm{P}=100 \mathrm{mbar}$. Due to a lack of sensitivity and resolution, it was not possible to measure at lower pressure and to fully resolve the tetrahedral splitting of $\mathrm{CF}_{4}$ rotational lines. Moreover, the ground state transitions with absorbances lower than 1\% (Figure 6, upper panel) were not observed. The first measurements of the tetrahedral split components of distortion-induced rotational lines of $\mathrm{CF}_{4}$ are presented in this work with the FP-TAS measurements performed in the $625 \mathrm{GHz}$ region. The middle panel of Figure 6 targets the frequency range accessible by FP-TAS. The $\mathrm{THz}$ spectrum of $\mathrm{CF}_{4}$ is simulated at a resolution of $100 \mathrm{kHz}$ with fully resolved and Doppler limited rotational lines at $\mathrm{P}=100 \mu \mathrm{bar}$. With a $1 \mathrm{~km}$ path-length, absorbances above $1 \%$ are reached for several transitions in the ground state and in the $v_{3}=1$ hot band. Finally, four examples of measured lines by FP-TAS in the $R(20)$ cluster are presented in the lower panel. The lines of the multiplet were measured individually with finesses between 2800 to 3250 and pressures between $80 \mu$ bar and $150 \mu$ bar. The frequency step was fixed to a few $\mathrm{kHz}$ and the time constant to $200 \mathrm{~ms}$. The SNR for the four lines of Figure 6 are measured between 20 to 120, which shows that the measurement of very weak $\mathrm{THz}$ line intensities below $10^{-28} \mathrm{~cm}^{-1} /\left(\right.$ molec cm$\left.{ }^{-2}\right)$ may be for now considered in $\mathrm{THz}$ spectroscopy. Considering this level of intensity now reachable, we can expect trace gas detection of $\mathrm{N}_{2} \mathrm{O}$ and $\mathrm{O}_{3}$ (Figure 4) by FP-TAS in the THz cavity at a subppm LOD, enough for a detection at atmospheric concentrations. 

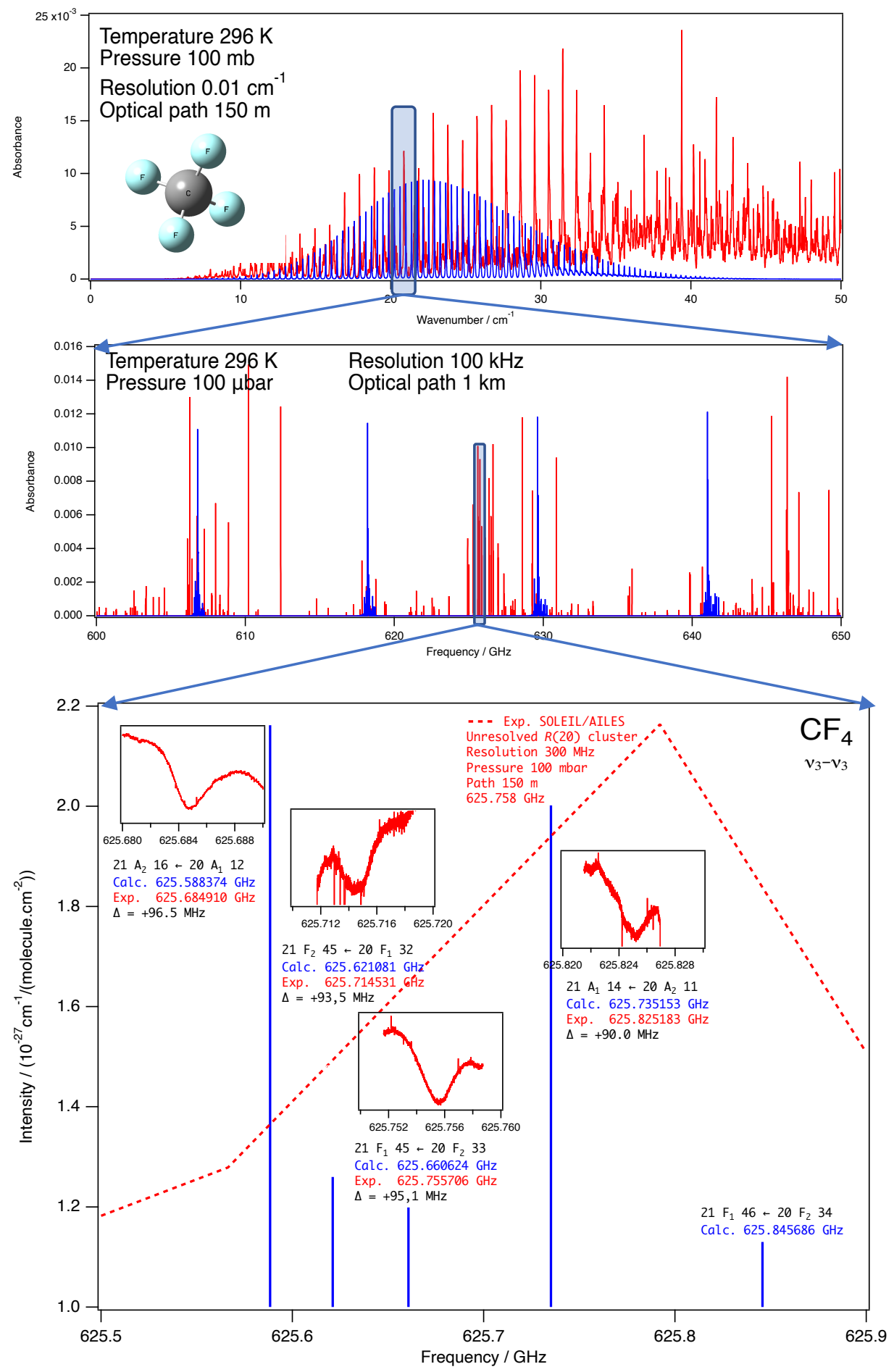

Figure 6. Upper panel: Simulation of the $\mathrm{CF}_{4} \mathrm{THz}$ absorbance in the conditions of the synchrotron-based FT-Far-IR measurements (see Ref. [36]), namely a resolution of $0.01 \mathrm{~cm}^{-1}$, a gas pressure of $100 \mathrm{mbar}$ and a path-length of $150 \mathrm{~m}$. Middle panel: Simulation of the $\mathrm{CF}_{4} \mathrm{THz}$ absorbance measured in the frequency range accessible by FP-TAS at a resolution of $100 \mathrm{kHz}$ with a gas pressure of $100 \mu$ bar and an effective path-length of $1 \mathrm{~km}$. For both simulations, ground state transitions are in blue, $v_{3}=1$ hot band transitions are in red. Lower panel: Zoom on experimental individual rotational lines $\left(R(20)\right.$ cluster in the $v_{3} \leftarrow v_{3}$ hot band) measured by FP-TAS. The experimental THz frequencies are determined by the microwave synthesiser used to drive the AMC. The microwave synthesiser is referenced to a time signal provided by a GPS receiver. The calculated frequencies are determined using the STDS software [27]. Dashed red line correspond to the FT-Far-IR synchrotron-based measurements at a pressure of $100 \mathrm{mbar}$ and a resolution of $0.01 \mathrm{~cm}^{-1}$. 


\section{Conclusions}

The present article highlights the best performances reached by rotational submmwave/THz long-path absorption spectroscopy of important atmospheric GHGs. The results obtained on $\mathrm{CH}_{4}$ and $\mathrm{CF}_{4}$ demonstrate that the weakly intense centrifugal distortioninduced rotational lines are measurable with a high degree of accuracy thanks to the progress of $\mathrm{THz}$ gas phase high-resolution spectroscopy. Several percents of methane absorbances with a path-length of $20 \mathrm{~m}$ may be measured above $2 \mathrm{THz}$ by a cw-THz photomixing source coupled to a White-type multi-pass cell. Thanks to a frequency metrology based on a frequency comb, the rotational line centers are measured with an accuracy competitive with those of electronic synthesizers and few $\mathrm{cw}-\mathrm{THz}$ measurements are able to improve the ground state low-order molecular parameters of the $\mathrm{CH}_{4}$ spherical top [13]. The study of $\mathrm{CH}_{4}$ has been focused on $\mathrm{THz}$ line position analysis but absolute intensities measurements are required for quantitative spectrosocopy of methane. Such analysis requires the improvement of the spectrometer sensitivity. For this purpose, photomixers using a metallic mirror-based FP cavity could be tested at short term in order to increase significantly the power of the source [37]. Next a new generation of spectrometers has to be imagined allowing technological breakthroughs in the $\mathrm{THz}$ frequency gap. The use of cavity enhanced techniques initially developed in the IR hold great promise, as demonstrated by the results on $\mathrm{CF}_{4}$ presented in this study where the tetrahedral splitting of $\mathrm{CF}_{4}$ rotational lines have been measured and resolved by FP-TAS in the submm-wave domain. This technique based on a high finesse cavity allows reaching $\mathrm{km}$ effective path-length in a compact gas cell. According to the $\mathrm{CF}_{4}$ lines measured in Figure 6 (lower panel), FP-TAS with a finesse $>3200$ should be able to measure rotational lines with SNR $>3$ for transitions with minimal intensities up to $10^{-28} \mathrm{~cm}^{-1} /\left(\right.$ molec. $\left.\mathrm{cm}^{-2}\right)$. The results presented in this article constitute a first step of a larger study of the $\mathrm{CF}_{4}$ pure rotational spectrum by FP-TAS: numerous lines in the 600-650 GHz frequency range (see Figure 6, middle panel) with absorbances $>1 \%$ have to be measured, especially the ground state lines. The measured line frequencies will be included in a global fit of the $\mathrm{CF}_{4}$ ground state and $v_{3}=1$ molecular parameters in order to update the TFMeCaSDa database [38]. No doubt that the THz spectroscopy studies of GHGs such as $\mathrm{CH}_{4}$ and $\mathrm{CF}_{4}$ have to be continued. In addition, new spectroscopic data may be also obtained by considering the asymmetric isotopologues of non polar GHGs. In particular, with the high sensitivity offered by our THz cavity, it will probably possible to measure the $\mathrm{R}(27)$ and $\mathrm{R}(28)$ rotational transitions of asymmetric ${ }^{16} \mathrm{O}^{12} \mathrm{C}^{18} \mathrm{O}$ and to improve its ground state constants fitted only with low $J$ value $\mathrm{cm}$ - and mm-wave transitions [39].

On the other hand, the trace gas detection of non or weakly polar GHGs at atmospheric concentration can not be seriously considered. In the case of the polar stable $\mathrm{N}_{2} \mathrm{O}$ and unstable $\mathrm{O}_{3}$ GHG the situation is different since we demonstrated our ability to measure these molecules at trace levels. For the first time, $\mathrm{THz}$ spectroscopy was used for a direct monitoring of molecular species in an atmospheric simulation chamber. Thanks to an especially designed Chernin multi-pass cell allowing to adjust a $\mathrm{THz}$ pathlength from $120 \mathrm{~m}$ to $240 \mathrm{~m}$, quantitative rotational measurements of $\mathrm{N}_{2} \mathrm{O}$ and $\mathrm{O}_{3}$ traces were performed. Right now, the accessible detection levels for both compounds are limited to tens of ppm. We are working on a correct baseline modelization in order to remove its variations due to multiple interfering stationary waves in the Chernin cell. Anyway, the first results obtained in CHARME with the coupling of a THz source to the MultiCHARME setup opens new possibilities especially for the monitoring of stratospheric reaction processes at low-pressure. In particular, the versatility of the electronic sources will allows performing time-resolved quantitative spectroscopies of reactants, oxidants and products involved in targeted reactions occurring in the high altitude atmospheric layers. Moreover, it will be interesting to measure in CHARME, at different pressures, the THz self-continuum of water absorption with the AMC coupled to MultiCHARME and to compare our spectra with those recently performed with the coherent $\mathrm{THz}$ synchrotron radiation coupled to the White-type cell shown in Figure 1 (right part) [40]. Finally, the high-finesse THz cavity has 
also to be employed for the detection of stable $\mathrm{N}_{2} \mathrm{O}$ and unstable $\mathrm{O}_{3}$ GHG. Next studies will be dedicated to verify if $\mathrm{N}_{2} \mathrm{O}$ and $\mathrm{O}_{3}$ submm-wave transitions could be measured at tropospheric $(330 \mathrm{ppb})$ and stratospheric $(7500 \mathrm{ppb})$ concentrations by FP-TAS.

Author Contributions: conceptualization, A.C. and V.B.; methodology, A.C., F.H., G.M., R.B., J.D., É.F. and V.B.; software, F.H.; validation, A.C. and V.B.; investigation, C.B., J.B., J.D., É.F, A.P. and A.C.; formal analysis, C.B., J.B., J.D., A.P. and V.B.; writing-original draft preparation, A.C.; writingreview and editing, F.H., R.B., J.B. and V.B.; supervision, A.C., G.M. and F.H.; project administration, A.C., V.B. and G.M.; funding acquisition, A.C., G.M. and É.F. All authors have read and agreed to the published version of the manuscript.

Funding: This work was supported by the CaPPA project (Chemical and Physical Properties of the Atmosphere) funded by the French National Research Agency (ANR-11-LABX-0005-01) and the CLIMIBIO program supported by the Hauts-de-France Regional Council, the French Ministry of Higher Education and Research and the European Regional Development Fund. C.B. and J.D. were also funded by CLIMIBIO. The photomixing $\mathrm{cw}-\mathrm{THz}$ spectrometer has been funded both by the Délégation Générale pour 1'Armement (DGA, ProjetANR-11-ASTR-0035), the Institut de Recherche en Environnement Industriel (IRENI) and the European Commission via the Interreg IVA-2seas (Cleantech Project). MultiCHARME was founded by the University of Littoral and its Research Quality Bonus. The THz cavity and A.P. were funded by the Satt-Nord (project Teraspec-M0407), the French ANR (ANR-15-CE29-0017) and the European Regional Development Fund (INTERREG V FR-WA-VL 1.2.11).

Acknowledgments: We thank: (i) the AILES beamline team for the synchrotron-based FT-THz experiments, especially the beamline manager P. Roy and O. Pirali in charge of the FT-FIR measurements in the White type cell; (ii) W. Zhao and B. Fang from the Anhui Institut of Optics and Fine Mechanics (Hefei, China) for the development of the Chernin cell; (iii) C. Coeur, N. Houzel and P. Kulinski from LPCA (Dunkirk, France) for their assistance during the measurements in the CHARME chamber.

Conflicts of Interest: The authors declare no conflict of interest.

$\begin{array}{ll}\text { Abbreviations } \\ \text { The following abbreviations are used in this manuscript: } \\ \text { ACE } & \text { Atmospheric Chemistry Experiment } \\ \text { AILES } & \text { Advanced Infrared beamLine Exploited for Spectroscopy } \\ \text { AMC } & \text { Amplified Multiplier Chains } \\ \text { CFCs/HCFCs } & \text { ChloroFluoroCarbons } \\ \text { CHARME } & \text { CHamber for the Atmospheric Reactivity and the Metrology of the Environment } \\ \text { cW-THz } & \text { continuous-wave Terahertz } \\ \text { FFT } & \text { Fast Fourier Transform } \\ \text { FP-TAS } & \text { Fabry-Perot Terahertz Absorption Spectroscopy } \\ \text { FSR } & \text { Free Spectral Range } \\ \text { FTS } & \text { Fourier Transform Spectrometer } \\ \text { GHG } & \text { Greenhouse gas } \\ \text { HITRAN } & \text { HIgh-resolution TRANsmission molecular absorption database } \\ \text { IASI } & \text { Infrared Atmospheric Sounding Interferometer } \\ \text { IR } & \text { InfraRed } \\ \text { LOD } & \text { Level of Detection } \\ \text { LTG-AsGa } & \text { Low-Temperature Grown-Arsenide Gallium } \\ \text { MLS } & \text { Microwave Limb Sounder } \\ \text { NEP } & \text { Noise Equivalent Power } \\ \text { SCISAT } & \text { SCIence Satellite } \\ \text { SNR } & \text { Signal to Noise Ratio } \\ \text { SOLEIL } & \text { Source Optimisée de Lumière d'Énergie Intermédiaire du LURE } \\ \text { STDS } & \text { Spherical-Top Data System } \\ \text { TALIS } & \text { THz Atmospheric Limb Sounder } \\ \text { TES } & \text { Tropospheric Emission Spectrometer } \\ \text { TFMeCaSDa } & \text { TetraFluoroMethane Calculated Spectroscopic Databases }\end{array}$




$\begin{array}{ll}\text { THz-TDS } & \text { Terahertz-Time Domain Spectroscopy } \\ \text { LO } & \text { Local Oscillator } \\ \text { UV } & \text { Ultraviolet } \\ \text { ZBD } & \text { Zero Bias Detector }\end{array}$

\section{References}

1. U.S. Environmental Protection Agency; Global Greenhouse Gas Emissions Data; U.S. Environmental Protection Agency. The Burning of Coal, Natural Gas, and Oil for Electricity and Heat is the Largest Single Source of Global Greenhouse Gas Emissions. In Global Greenhouse Gas Emission Data; U.S. Environmental Protection Agency: Washington, DC, USA, 2019.

2. Ravishankara, A.R.; Solomon, S.; Turnipseed, A.A.; Warren, R.F. Atmospheric lifetimes of long-lived halogenated species. Science 1993, 259, 194-199. [CrossRef] [PubMed]

3. Butler, J.; Montzka, S. The NOAA Annual Greenhouse Gas Index (AGGI); NOAA Global Monitoring Laboratory/Earth System Research Laboratories: Washington, DC, USA, 2016.

4. Myhre, G.; Shindell, D.; Bréon, F.-M.; Collins, W.; Fuglestvedt, J.; Huang, J.; Koch, D.; Lamarque, J.-F.; Lee, D.; Mendoza, B.; et al. Anthropogenic and Natural Radiative Forcing. In Climate Change 2013: The Physical Science Basis. Contribution of Working Group I to the Fifth Assessment Report of the Intergovernmental Panel on Climate Change; Stocker, T.F., Qin, D., Plattner, G.-K., Tignor, M., Allen, S.K., Boschung, J., Nauels, A., Xia, Y., Bex, V., Midgley, P.M., Eds.; Cambridge University Press: Cambridge, UK; New York, NY, USA, 2013.

5. Clerbaux, C.; Boynard, A.; Clarisse, L.; George, M.; Hadji-Lazaro, J.; Herbin, H.; Hurtmans, D.; Pommier, M.; Razavi, A.; Turquety, S.; et al. Monitoring of atmospheric composition using the thermal infrared IASI/MetOp sounder. Atmos. Chem. Phys. 2009, 9, 6041-6054. [CrossRef]

6. Bernath, P.-F. The Atmospheric Chemistry Experiment (ACE). J. Quant. Spectrosc. Radiat. Transf. 2017, 186, 3-16.

7. Beer, R. TES on the Aura Mission: Scientific Objectives, Measurements, and Analysis Overview. IEEE Trans. Geosci. Remote Sens. 2006, 44, 1102-1105. [CrossRef]

8. Froidevaux, L.; Livesey, N.J.; Read, W.G.; Jiang, Y.B.; Jimenez, C.; Filipiak, M.J.; Schwartz, M.J.; Santee, M.L.; Pumphrey, H.C.; Jiang, J.H.; et al. Early validation analyses of atmospheric profiles from EOS MLS on the aura Satellite. IEEE Trans. Geosci. Remote Sens. 2006, 44, 1106-1121. [CrossRef]

9. Wang, W.; Wang, Z.; Duan, Y. Performance evaluation of THz Atmospheric Limb Sounder (TALIS) of China. Atmos. Meas. Tech. 2020, 13, 13-38. [CrossRef]

10. Ha, T.; Cuisset, A.; Payan, S.; Schwell, M.; Té, Y.; Tomasini, L.; Giraud-Héraud, Y. The first Vietnam School of Earth Observation: Atmospheric Remote Sensing and Molecular Spectroscopy. Vietnam J. Earth Sci. 2019, 41, 138-155. [CrossRef]

11. Kim, G.-R.; Lee, H.-B.; Jeon, T.-I. Terahertz Time-Domain Spectroscopy of Low Concentration $\mathrm{N}_{2} \mathrm{O}$ using Long-Range multi-pass Gas Cell. IEEE Trans. THz Sci. Technol. 2020, 10, 524-530.

12. Brubach, J.-B.; Manceron, L.; Rouzières, M.; Pirali, O.; Balcon, D.; Tchana, F.; Boudon, V.; Tudorie, M.; Huet, T.; Cuisset, A.; et al Performance of the AILES THz-infrared beamline on SOLEIL for high resolution spectroscopy. AIP Conf. Proc. 2010, 1214, 81-84.

13. Bray, C.; Cuisset, A.; Hindle, F.; Mouret, G.; Bocquet, R.; Boudon, V. Spectral lines of methane measured up to $2.6 \mathrm{THz}$ at sub-MHz accuracy with a cw-THz photomixing spectrometer: Line positions of rotational transitions induced by centrifugal distortion. $J$. Quant. Spectrosc. Radiat. Transf. 2017, 203, 349-354. [CrossRef]

14. Hindle, F.; Yang, C.; Mouret, G.; Cuisset, A.; Bocquet, R.; Lampin, J.-F.; Blary, K.; Peytavit, E.; Akalin, T.; Ducournau, G. Recent Developments of an Opto-Electronic THz Spectrometer for High-Resolution Spectroscopy. Sensors 2009, 9, 9039-9057. [CrossRef] [PubMed]

15. Hindle, F.; Mouret, G.; Eliet, S.; Guinet, M.; Cuisset, A.; Bocquet, R.; Yasui, T.; Rovera, D. Widely tunable THz synthesizer. Appl. Phys. B 2011, 104, 763-769. [CrossRef]

16. Mouret, G.; Guinet, M.; Cuisset, A.; Croize, L.; Eliet, S.; Bocquet, R.; Hindle, F. Versatile Sub-THz Spectrometer for Trace Gas Analysis. IEEE Sens. J. 2013, 13, 133-138. [CrossRef]

17. Hindle, F.; Bocquet, R.; Pienkina, A.; Cuisset, A.; Mouret, G. Terahertz gas phase spectroscopy using a high-finesse Fabry-Pérot cavity. Optica 2019, 6, 1449-1454. [CrossRef]

18. White, J.U. Long optical paths of large aperture. J. Opt. Soc. Am. 1942, 32, 285-288.

19. Podobedov, V.-B.; Plusquellic, D.-F.; Fraser, G.-T. Investigation of the water-vapor continuum in the THz region using a multi-pass cell. J. Quant. Spectrosc. Radiat. Transf. 2005, 91, 287-295. [CrossRef]

20. Winnewisser, M.; Winnewisser, B.-P.; Stein, M.; Birk, M.; Wagner, G.; Winnewisser, G.; Yamada, K.; Belov, S.-P.; Baskakov, O.-I. Rotational Spectra of cis-HCOOH, trans-HCOOH, and trans-H ${ }^{13} \mathrm{COOH}$. J. Mol. Spectrosc. 2002, 216, 259-265. [CrossRef]

21. Boudon, V.; Pirali, O.; Roy, P.; Brubach, J.-B.; Manceron, L.; Auwera, J.-V. The high- resolution far-infrared spectrum of methane at the SOLEIL synchrotron. J. Quant. Spectrosc. Radiat. Transf. 2010, 111, 1117-1129.

22. Harmon, S.-A.; Cheville, R.-A. Part-per-million gas detection from long-baseline THz spectroscopy. Appl. Phys. Lett. 2004, 85, 2128-2130. [CrossRef]

23. Gordon, I.-E.; Rothman, L.-S.; Hill, C.; Kochanov, R.V.; Tan, Y.; Bernath, P.F.; Birk, M.; Boudon, V.; Campargue, A.; Chance, K.V.; et al. The HITRAN2016 Molecular Spectroscopic Database. J. Quant. Spectrosc. Radiat. Transf. 2017, 203, 3-69. [CrossRef]

24. Available online: https:/ / hitran.iao.ru (accessed on 26 January 2021). 
25. Sanzharov, M.; Auwera, J.-V.; Pirali, O.; Roy, P.; Brubach, J.-B.; Manceron, L.; Gabard, T.; Boudon, V. Self and N 2 collisional broadening of far-infrared methane lines measured at the SOLEIL synchrotron. J. Quant. Spectrosc. Radiat. Transf. 2012, 113, 1874-1886. [CrossRef]

26. Amyay, B.; Gardez, A.; Georges, R.; Biennier, L.; Vander Auwera, J.; Richard, C.; Boudon, V. New investigation of the $v_{3}$ C-H stretching region of ${ }^{12} \mathrm{CH}_{4}$ through the analysis of high temperature infrared emission spectra. J. Chem. Phys. 2018, 148, 134306. [CrossRef] [PubMed]

27. Wenger, C.; Champion, J.P. Spherical top data system (STDS) software for the simulation of spherical top spectra. J. Quant. Spectrosc. Radiat. Transf. 1998, 59, 471-480.

28. Wenger, C.; Boudon, V.; Rotger, M.; Sanzharov, J.P.; Champion, J.P. XTDS and SPVIEW: Graphical tools for the analysis and simulation. J. Mol. Spectrosc. 2008, 251, 102-113. [CrossRef]

29. Rothbart, N.; Schmaltz, K.; Hübers, H.-W. A Compact Circular multi-pass Cell for Millimeter-Wave/Terahertz Gas Spectroscopy. IEEE Trans. THz Sci. Technol. 2019, 10, 9-14. [CrossRef]

30. Chernin, S.-M. New generation of multi-pass systems in high resolution spectroscopy. Spectrochim. Acta Part A 1996, 52, 1009-1022. [CrossRef]

31. Tchana, F.K.; Willaert, F.; Landsheere, X.; Flaud, J.-M.; Lago, L.; Chapuis, M.; Herbeaux, C.; Roy, P.; Manceron, L. A new, low temperature long-pass cell for mid-infrared to terahertz spectroscopy and synchrotron radiation use. Rev. Sci. Instrum. 2013, 84, 093101. [CrossRef]

32. Meng, L.; Coeur, C.; Fayad, L.; Houzel, N.; Genevray, P.; Bouzidi, H.; Tomas, A.; Chen, W. Secondary organic aerosol formation from the gas-phase reaction of guaiacol (2-methoxyphenol) with $\mathrm{NO}_{3}$ radicals. J. Atmos. Environ. 2020, 240, 1117740. [CrossRef]

33. Decker, J.; Fertein, E.; Bruckhuisen, J.; Houzel, N.; Kulinski, P.; Fang, B.; Zhao, W.; Bocquet, R.; Hindle, F.; Mouret, G.; et al. MULTICHARME: A Chernin type multi-pass cell designed for IR and THz spectroscopies experiments in CHARME. 2021, manuscript in progress.

34. Deng, H.-B.; Li, F.-X.; Cai, Y.-H.; Xu, S.-Y. Waste anesthetic gas exposure and strategies for solution. J. Anesthes. 2018, 32, $269-282$.

35. Rey, M.; Chizhmakova, I.-S.; Nikitin, A.-V.; Tyuterev, V.-G. Understanding global infrared opacity and hot bands of greenhouse molecules with low vibrational modes from first-principles calculations: The case of $\mathrm{CF}_{4}$. Phys. Chem. Chem. Phys. 2018, 20, 21008-21033. [CrossRef]

36. Boudon, V.; Carlos, M.; Richard, C.; Pirali, O. Pure rotation spectrum of $\mathrm{CF}_{4}$ in the $v_{3}=1$ state using $\mathrm{THz}$ synchrotron radiation. J. Mol. Spectrosc. 2018, 348, 43-46. [CrossRef]

37. Peytavit, E.; Latzel, P.; Pavanello, F.; Ducournau, G.; Lampin, J.-F. CW source based on photomixing with output power reaching $1.8 \mathrm{~mW}$ at $250 \mathrm{GHz}$. IEEE Electron Device Lett. 2013, 34, 1277-1279. [CrossRef]

38. Richard, C.; Boudon, V.; Rotger, M. Calculated spectroscopic databases for the VAMDC portal: New molecules and improvements. J. Quant. Spectrosc. Radiat. Transf. 2020, 251, 107096. [CrossRef]

39. Endo, Y.; Yoshida, K.; Saito, S.; Horota, E. The microwave spectrum of carbon dioxide—18 O. J. Chem. Phys. 1980, 73, 3511-3512. [CrossRef]

40. Odintsova, T.-A.; Tretyakov, M.-Y.; Zibarova, A.-O.; Pirali, O.; Roy, P.; Campargue, A. Far-infrared self-continuum absorption of $\mathrm{H}_{2}^{16} \mathrm{O}$ and $\mathrm{H}_{2}^{18} \mathrm{O}\left(15-50 \mathrm{~cm}^{-1}\right)$. J. Quant. Spectrosc. Radiat. Transf. 2019, 227, 190-200. 